\title{
INCREASED GLUCOSE METABOLISM DURING LONG- DURATION RECURRENT INHIBITION OF HIPPOCAMPAL PYRAMIDAL CELLS ${ }^{1}$
}

\author{
ROBERT F. ACKERMANN, ${ }^{2}$ DAVID M. FINCH, THOMAS L. BABB, AND JEROME ENGEL, JR. \\ Reed Neurological Research Center, and Brain Research Institute, University of California, Los Angeles, School of Medicine and \\ Center for Health Sciences, Los Angeles, California 90024
}

Received January 3, 1983; Revised August 23, 1983; Accepted August 23, 1983

\begin{abstract}
The locally subnormal brain metabolism observed in some experiments utilizing the Sokoloff 2deoxyglucose (2-DG) method has often been attributed to postsynaptic inhibition despite the fact that inhibitory postsynaptic potentials are themselves caused by energy-requiring mechanisms. To explore this issue, neurophysiologically confirmed long-duration recurrent inhibition of hippocampal pyramidal unit firing was induced by low frequency $(2$ to $4 \mathrm{~Hz}$ ) stimulation of the fornix for $60 \mathrm{~min}$ following intravenous infusion of $\left[{ }^{14} \mathrm{C}\right]-2-\mathrm{DG}$. The resulting autoradiograms showed that longduration suppression of pyramidal cell firing was accompanied by distinctly increased hippocampal 2-DG uptake, particularly in the stratum pyramidale, which contains a dense plexus of inhibitory interneuronal terminals upon pyramidal cells. Both the pyramidal inhibition and the increased 2DG uptake were confined to the ipsilateral hippocampus in animals with previously severed fornices and hippocampal commissures. In a second series of rats, the excitatory entorhinohippocampal "perforant path" (PP) was stimulated at low frequency $(2$ to $9 \mathrm{~Hz})$ following 2-DG administration. At 2 to $4 \mathrm{~Hz}$, each PP stimulation resulted in a brief burst of pyramidal unit firing followed by short-duration firing suppression; this result was associated with paradoxically decreased 2-DG uptake in the ipsilateral stratum moleculare. By contrast, 7 to $9 \mathrm{~Hz}$ entorhinal stimulation induced PP-mediated excitation immediately followed by powerful intrinsic hippocampal inhibition, evidenced by prolonged pyramidal unit suppression after each stimulation. This suppression was accompanied by increased 2-DG uptake in the dentate stratum moleculare and hippocampal stratum pyramidale. Thus it appeared that even with entorhinal stimulation, hippocampal 2-DG uptake was more closely associated with long-duration recurrent inhibition than with transient pyramidal excitation. Therefore, although it still remains possible that regions of hypometabolism observed in some previous 2-DG studies may actually reflect mild inhibition, other mechanisms such as disfacilitation are more likely mechanisms for this metabolic pattern.
\end{abstract}

The development by Sokoloff and his associates (Sokoloff, 1977; Sokoloff et al., 1977) of the $2-\left[{ }^{14} \mathrm{C}\right]$ deoxyglucose (2-DG) contact autoradiographic technique for estimating local metabolic rates has allowed numerous

\footnotetext{
${ }^{1}$ This work was supported by Grants NS-15654 and NS-16721 from the Public Health Service, and by Department of Energy Contract DEAM03-76-SF00012. We wish to acknowledge the assistance of Mr. Wrother Meredith, whose technical expertise was essential to the collection of the present data. We also gratefully acknowledge the assitance of Ms. Edith Barsky in typing and editing the manuscript. We are indebted to Dr. Charles Wilson for many helpful discussions and suggestions.

${ }^{2}$ To whom correspondence should be addressed, at Reed Neurological Research Center, UCLA School of Medicine and Center for Health Sciences, Los Angeles, CA 90024.
}

contributions to our understanding of functional relationships among brain nuclei under a broad variety of experimental conditions (for reviews see Plum et al., 1976; Sokoloff, 1981). However, several fundamental issues remain unclear, among them the role that neuronal inhibition plays in regional energy demand. In several 2DG studies it has been suggested that lateral inhibition may account for regions of subnormal metabolism located on the fringe of regions of supranormal metabolism (Collins, 1980; Colombo and Saporta, 1980; Kuhl et al., 1980; Tootell et al., 1981). Such an explanation presumes that the major cause of regional energy demand is the excitation and the consequently increased firing of principal (long-axoned) neurons. Thus it has been assumed that in regions of increased metabolism many principal 
neurons are excited and therefore fire at a high rate, whereas in regions of subnormal metabolism the firing of principal neurons is retarded by inhibitory postsynaptic potentials (IPSPs), resulting in decreased energy demand. However, there is no reason to expect that the energy requirements of synaptic inhibition should be dissimilar to those of synaptic excitation (cf. Coombs et al., 1955; Schwartz et al., 1979; Mata et al., 1980; for discussion see Collins, 1978; Caveness et al., 1980). First, IPSPs are themselves the product of inhibitory neuronal firing, often at high frequency (Renshaw, 1946; Eccles et al., 1954; Andersen et al., 1964b; Dichter and Spencer, 1969; Murphy and Renaud, 1969; McLennan and Miller, 1974; Finch and Babb, 1977; Schwartzkroin and Mathers, 1978; Anderson and Rutledge, 1979; Bland, et al., 1980; Buzsáki and Eidelberg, 1981; Knowles and Schwartzkroin, 1981), and transmitter release depends upon the arrival of action potentials into terminals (cf. Hagiwara and Tasaki, 1958; 'Takeuchi and 'Takeuchi, 1962). Thus, the energy-requiring ion-pumping mechanisms (Rang and Ritchie, 1968; Tang et al., 1980; see Cruetzfeldt, 1975 , for discussion) necessary for restoration of intraand extracellular ion concentrations following action potentials must operate in inhibitory presynaptic terminals (cf. Mata et al., 1980) during active inhibition. Second, energy is as necessary for the synthesis, release, and breakdown or reuptake of inhibitory transmitter as it is for excitatory transmitter. Third, hyperpolarization of postsynaptic neurons during IPSPs occurs as a consequence of ionic movements across their membranes, and such movements activate energy-requiring postsynaptic mechanisms that directly (Lux, 1971) or indirectly (Allen et al., 1977) pump hyperpolarizing ions against their concentration gradients. Therefore, a net reduction of regional 2-DG uptake should not be expected under inhibitory states unless postsynaptic inhibition is "efficient;" i.e., the above-described metabolic costs of postsynaptic inhibition must be less than the net metabolic savings that result when a region's principal neurons fire at significantly reduced rates.

The goal of the present experiments was to provide direct information concerning the metabolic demands of recurrent inhibition. The hippocampal formation was chosen as a model system because its neuroanatomy and neurophysiology have been well characterized and because in the hippocampus it is possible to selectively activate powerful interneuronal inhibitory circuits that suppress the firing of pyramidal neurons for long periods (see "Materials and Methods"). Hippocampal recurrent and lateral inhibition were elicited by electrically stimulating either the fimbria or the perforant path. The results demonstrated that dramatic increases in hippocampal glucose utilization can occur in the presence of profound inhibition of pyramidal cell firing. Because of the ubiquity of inhibition in neuronal function (Andersen and Eccles, 1962; Eccles, 1967, 1969), this finding has specific implications for the interpretation of 2-DG metabolic studies of CNS function and general significance for our understanding of the metabolic demands of excitatory versus inhibitory neuronal activity.

\section{Materials and Methods}

Rationale. The relative simplicity and spatial regularity of hippocampal structure makes possible the analysis of hippocampal 2-DG uptake patterns in terms of excitatory versus inhibitory mechanisms. Hippocampal inputs and outputs are largely restricted to a few pathways. Two of them were studied here: the fimbria-fornix (FF), which comprises hippocamposeptal and septohippocampal tracts (Meibach and Siegel, 1977a, b; Swanson and Cowan, 1977, 1979), and the perforant path (PP), which is an important input to the hippocampal formation from the entorhinal cortex (Lorente de Nó, 1934; Ramón y Cajal, 1955).

Electrical FF stimulation elicits powerful intrinsic recurrent inhibition within the hippocampus (Kandel et al., 1961) (Fig. 1). The antidromic FF impulses enter Ammon's horn and then propagate orthodromically along hippocampal pyramidal cell collaterals to excitatory terminals upon hippocampal interneurons (Knowles and Schwartzkroin, 1981) whose somata are situated primarily in stratum pyramidale and adjacent stratum oriens (Lorente de Nó, 1934; Ramón y Cajal 1955; Ribak et al., 1978; Schwartzkroin and Mathers, 1978). In turn, interneuronal cell axons branch extensively to terminate in a dense synaptic plexus upon the pyramidal cell bodies (Lorente de Nó, 1934), where they exert a powerful inhibitory influence (Andersen et al., 1964a, b). Thus, each stimulation of the FF produces: (1) at most, one antidromic action potential in each affected pyramidal neuron (Kandel et al., 1961), (2) a sustained excitatory burst in basket cells (Andersen et al., 1964b; Finch and Babb, 1977; Schwartzkroin and Mathers, 1978), and (3) a consequent large and long-lasting IPSP that suppresses firing in pyramidal neurons (Kandel et al., 1961; Andersen et al., 1964a; Knowles and Schwartzkroin, 1981).

Less powerful recurrent inhibitory circuitry is present in the dentate gyrus. Perforant path terminals excite dentate granule cells (Andersen et al., 1966a; Dudek et al., 1976; McNaughton and Barnes, 1977) and hippocampal pyramidal cells (Andersen et al., 1966b; Doller and Weight, 1982). Granule cell collaterals excite dentate interneurons (Buzsáki and Eidelberg, 1981) that in turn inhibit the granule cells (Andersen et al., 1966a; Dudek et al., 1976; Bland et al., 1980). The granule cells' main terminals ("mossy fibers") also excite pyramidal cells and can thereby induce hippocampal recurrent inhibition (Yamamoto, 1972). As a consequence of these anatomical and physiological relationships, PP stimulation can produce: (1) direct excitation of granule cells followed by dentate interneuronal inhibition of granule cells, and (2) direct and indirect excitation of pyramidal cells, followed by hippocampal interneuronal inhibition of pyramidal cells.

Subjects. Subjects were 20 adult male Sprague-Dawley albino rats (Simonsen Laboratories). In 6 of the animals the FF was stimulated, in 11 animals the entorhinal region was stimulated, and in the remaining 3 animals (controls) FF and entorhinal electrodes were positioned as usual, but no current was passed. In 6 of the 20 


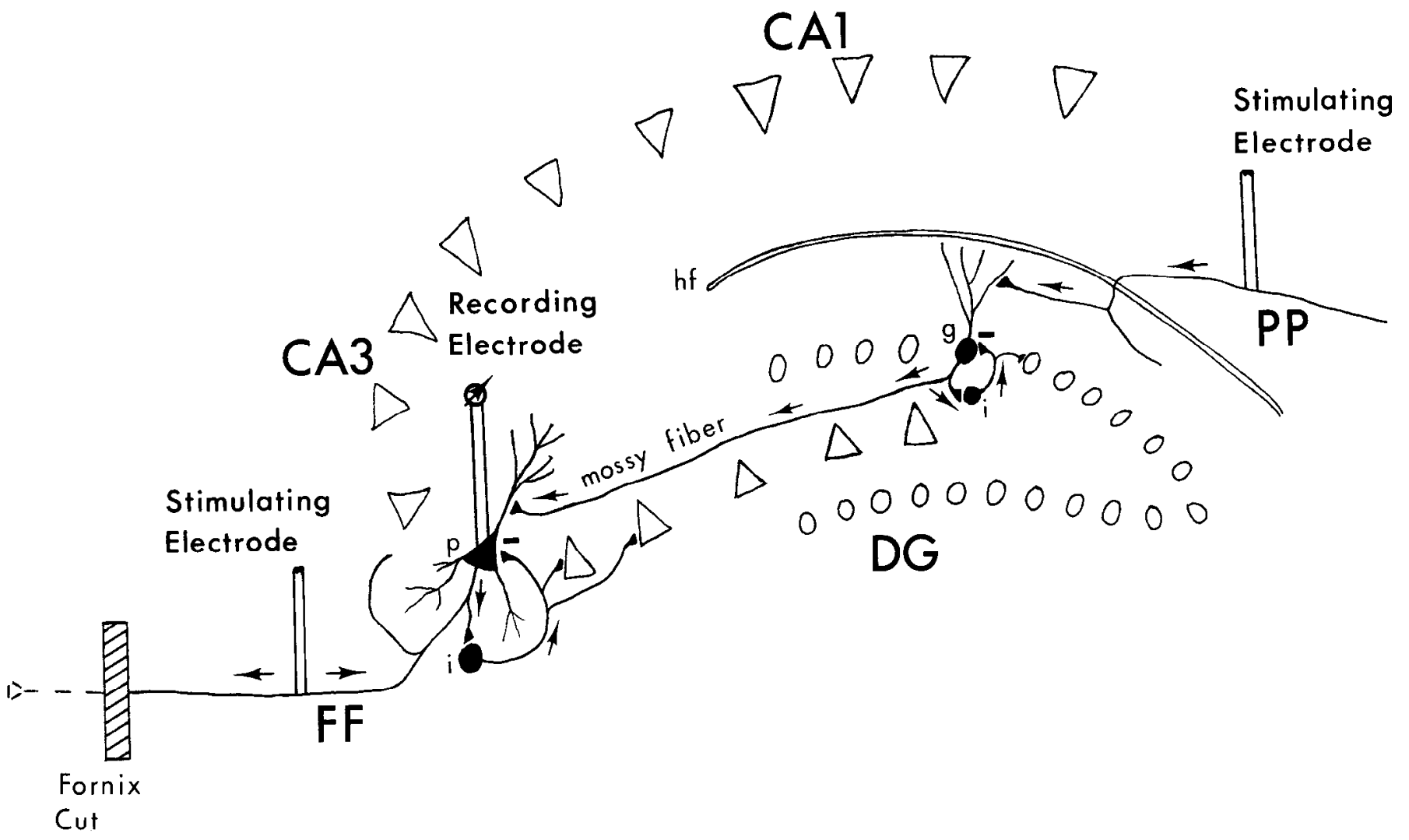

Figure 1. Hippocampal circuitry. In the first experiment the fimbria-fornix $(F F)$ was stimulated; in the second experiment the perforant path $(P P)$ was stimulated. In both experiments pyramidal $(p)$ unit activity was recorded. The cross-halched bar indicates the relative position of fornix cuts. $h f$, hippocampal fissure; $i$, interneuron; $g$, granule cell; $D G$, dentate gyrus granule cell layer; CA1-CA3, hippocampal pyramidal cell layer; $\rightarrow$, direction of neuronal spike propagation;-,inhibitory synapse.

animals, 3 of the FF group and 3 of the entorhinal group, the fornices and hippocampal commissures were surgically sectioned with a blunt wire probe (Finch and Babb, 1980) at least 2 weeks before the 2-DG experiments. This allowed sufficient time for the severed fibers' distal segments to degenerate (Daitz and Powell, 1954), thereby isolating the hippocampi from the septum and from each other, and also assuring that stimulating the FF caudal to the cut would excite (antidromically) only the surviving proximal segments of hippocamposeptal fibers (Daitz and Powell, 1954) (Fig. 1). As a consequence, hippocampal recurrent inhibitory circuitry would be activated in the absence of orthodromic excitation mediated by septohippocampal fibers (Kandel et al., 1961). Interrruption of the hippocampal commissures confined stimulation effects to the ipsilateral hippocampus, allowing use of the contralateral hippocampus as a within-subject control.

Surgery. Each animal was anesthetized with a mixture of sodium pentobarbital and chloral hydrate (EquiThesin (Janssen Pharmaceutica Inc.), $3.25 \mathrm{ml} / \mathrm{kg}$, i.p.), and a jugular vein was cannulated toward the heart. The animal was placed immediately into a stereotaxic device (David Kopf Instruments) and prepared for electrical stimulation and recording. Supplemental doses of EquiThesin $(0.3 \mathrm{ml}$, i.m.) were administered as necessary to maintain an anesthetic level at which spontaneous movements were absent, but at which leg withdrawal reflexes to a pinch remained. Rectal temperature was maintained at $37^{\circ} \pm 0.5^{\circ} \mathrm{C}$. Stimulation was delivered through bipolar electrodes constructed of twisted strands of $150-\mu \mathrm{m}$ diameter insulated stainless steel wire cut perpendicularly across their tips. All animals had FF electrodes (coordinates from the König and Klippel (1975) atlas, in $\mathrm{mm}$ : A 6.7 ; L 1.2 to $3.0 ; \mathrm{H} 1.5$; incisor bar 2.4 below the interaural line) for the purpose of precisely locating the hippocampal recording electrodes (see below) and for stimulating the FF under 2-DG in the FF-stimulation group. Fourteen animals had stimulation electrodes aimed at the entorhinal region (A 1.5 to $2.0 ; \mathrm{L} 4.8$ to 5.6 ; $\mathrm{H}-1.6) ; 11$ were used to stimulate the $\mathrm{PP}$, and 3 were unstimulated controls. Each animal had two fine wire bipolar recording electrodes constructed of twisted strands of $50-\mu \mathrm{m}$-diameter insulated stainless steel wire cut perpendicularly across their tips, placed bilaterally in or near the caudal $\mathrm{CA}_{3}$ or $\mathrm{CA}_{1}$ pyramidal cell layer (A 3.3; L 4.8; H 1.5).

Recording and stimulation. Hippocampal multiple-unit activity was recorded differentially between the tips of each bipolar fine wire recording electrode, amplified, filtered $(330 \mathrm{~Hz}$ to $10 \mathrm{KHz})$, and displayed continuously on a dual-beam oscilloscope; this assured detection of 
any afterdischarges that might occur. The FF and hippocampal electrodes were always lowered to their final positions simultaneously, with continuous low frequency stimulation delivered through the FF electrode. This allowed final positioning of each electrode under physiological control to maximize the characteristic inhibitory response of pyramidal cells to FF stimulation; typically this response was a short-latency ( $5 \mathrm{msec})$, longduration (up to $700 \mathrm{msec}$ ) cessation of pyramidal unit firing.

Electrical stimulation consisted of $0.2-\mathrm{msec}$ square wave capacitance-coupled pulses that were isolated from ground. Stimulation intensity varied between 180 and $800 \mu \mathrm{A}$, and stimulation frequency varied between 1.7 and $9.1 \mathrm{~Hz}$ across animals, but both were constant within animals (Tables I and II). Post-stimulus time histograms were computed on-line with a neuronal pulse window discriminator and a signal averager (Dagan 4800). Recorded (FM) samples of unit activity obtained before, during, and after the stimulation/2-DG experiments were later played back off-line on a wide-band oscillograph (Siemens Oscillomink B).

For each animal, the duration of stimulation-induced inhibition was calculated from the oscillograph records by measuring the time between the stimulus artifact and the resumption of sustained unit firing, averaged over a sample of 25 consecutive stimulations that occurred either immediately before or within the first several minutes after 2-DG administration. In one case (animal 16 ), in which unit records were judged inadequate for the above-described analysis, inhibition duration was estimated from a post-stimulation time histogram comprising 32 sweeps.

2-DG administration and autoradiography. Very low frequency $(0.5 \mathrm{~Hz})$ stimulation was begun during the 10 min base line period. Toward the end of the base line period, the stimulus frequency was increascd gradually until the predetermined experimental frequency was achieved; the purpose of this procedure was to avoid inducing an afterdischarge. After 2 min of stimulation at the experimental frequency, a $0.5-\mathrm{ml}$ bolus of $\left[{ }^{14} \mathrm{C}\right]-2-\mathrm{DG}$ (100 $\mu \mathrm{Ci} / \mathrm{kg}$ ) was injected into the jugular cannula over a 30 -sec period. The stimulation then continued for an additional $60 \mathrm{~min}$. Following a 1 -min post-stimulation base line recovery period, an overdose of anesthetic was administered through the cannula, and the animal was immediately perfused through the heart with $40 \mathrm{ml}$ of normal saline, followed by $40 \mathrm{ml}$ of $10 \%$ formalin. The brain was rapidly removed and frozen in pulverized dry ice. Frozen brains were sectioned in a cryostat at $-15^{\circ} \mathrm{C}$; every $200 \mu \mathrm{m}, 20$ - and $40-\mu \mathrm{m}$ sections were collected by thawing them on coverslips and immediately drying them on a warming tray. Together with calibrated poly- $\left[{ }^{14} \mathrm{C}\right]$ methyl methacrylate standards (Amersham), dried sections were placed in contact with the emulsion of $\mathrm{x}$-ray film (Kodak NMB-1) inside a spring-loaded $x$-ray cassette for 7 to 14 days and then developed in an automatic developing machine (Kodak X-OMAT, model SP). Accumulation of $2-\mathrm{DG}$ by hippocampal structures was measured from the autoradiograms with an optical densitometer (Sargent-Welch, model PPD) having a $250-\mu \mathrm{m}$ aperture. Optical density was linearly proportional to ${ }^{14} \mathrm{C}$ concentration within the standards' range. Hippocampal 2-DG accumulation was expressed as the ratio of its optical density to that of the midbrain reticular formation ventrolateral to the periaqueductal gray. Densitometric comparisons were also made between right and left strata moleculare in PP-stimulated animals.

Location of electrode tips. Electrode tips were localized by examination of the unstained tissue sections and from inspection of the autoradiograms. In several instances, electrode tip localization was confirmed by subsequently staining the relevant sections with cresyl violet, and with a Prussian blue iron reaction.

\section{Results}

Histology. All FF electrode placements were in the fimbria as intended, with the exception of one animal (no. 4) in which the electrode was displaced caudally to lie in the dentate gyrus of the anterior pole of the dorsal hippocampus. All PP electrodes were in the entorhinal cortex, the subiculum, or the perirhinal cortex. The fine wire recording electrodes were localized to the pyramidal cell body layer of hippocampal fields $\mathrm{CA}_{3}$ or $\mathrm{CA}_{1}$. In those animals which had undergone surgical section of both the fornix and the hippocampal commissure, the sections were judged complete. Completeness of the commissural sections was also confirmed electrophysiologically; evoked potentials in response to either FF or PP stimulation always occurred in the ipsilateral hippocampus but never occurred in the contralateral hippocampus of sectioned animals, in contrast to intact animals, in which bilateral responses always were obtained. The sites of stimulation, together with resulting inhibition durations and 2-DG effects are summarized in Tables I and II.

FF stimulation. This study's main result was a striking increase in hippocampal 2-DG uptake under the condition of profound suppression of hippocampal pyramidal cell firing. In five of six animals that received FF stimulation, there was an obvious increase in hippocampal 2DG uptake, particularly in localized regions of the $\mathrm{CA}_{3}$ (Figs. 2, 3, and $5 A$ ) and temporal $\mathrm{CA}_{1}$ pyramidal cell layers; the pyramidal layers are not normally distinct in adult rat 2-DG autoradiograms (Schwartz and Sharp, 1978; Di Rocco and Hall, 1981). Three of the animals (no.'s 7, 13, and 21) also had increased subicular uptake. The sixth animal (no. 4), which had its "FF" stimulating electrode displaced caudally into the dentate gyrus of the rostrodorsal hippocampus, failed to show any enhancement of hippocampal 2-DG uptake beyond the immediate vicinity of the electrode tip. In intact animals, enhanced 2-DG uptake was apparent in both hippocampi but was greater on the side ipsilateral to the stimulation. In the three fornix/hippocampal commissure-sectioned animals, enhanced 2-DG uptake was observed in the ipsilateral hippocampus, but not the contralateral (Fig. $5 A$ ), demonstrating that FF stimulation-induced enhancement of hippocampal 2-DG uptake did not depend upon septohippocampal-induced excitation.

The hippocampal pyramidal multiple-unit recordings obtained from these animals revealed that the enhanced hippocampal 2-DG uptake was associated with profound, sustained suppression of pyramidal unit firing (see Table 
TABLE I

Fimbria-fornix (FF) stimulation

\begin{tabular}{ccccccl}
\hline Animal No. & $\begin{array}{c}\text { Condition of FF } \\
\text { and Hippocampal } \\
\text { Commissures }\end{array}$ & $\begin{array}{c}\text { Stimulation } \\
\text { Parameters }\end{array}$ & $\begin{array}{c}\text { Duration of } \\
\text { Inhibition } \\
(\mathrm{msec})\end{array}$ & $\begin{array}{c}\text { Hippocampal } \\
\text { 2-DG Ratio }\end{array}$ & \multicolumn{1}{c}{$\begin{array}{c}\text { Locus of Increased } \\
\text { Hippocampal 2-DG Uptake }\end{array}$} \\
\hline 3 & severed & 1.7 & 180 & 293 & 1.49 & ipsilateral: ventral $\mathrm{CA}_{1}, \mathrm{CA}_{3}$ \\
4 & severed & 1.7 & 180 & 203 & 0.82 & no change \\
6 & severed & 2.1 & 360 & 365 & 1.27 & ipsilateral: dorsal $\mathrm{CA}_{3}$, hilus \\
7 & intact & 1.6 & 180 & 600 & 2.19 & bilateral: caudal $\mathrm{CA}_{1}, \mathrm{CA}_{3}$, subiculum \\
13 & intact & 1.8 & 180 & 550 & 1.78 & bilateral: caudal $\mathrm{CA}_{1}, \mathrm{CA}_{3}$, subiculum \\
bilateral: caudal $\mathrm{CA}_{1}, \mathrm{CA}_{3}$, subiculum
\end{tabular}

${ }^{a}$ Mean hippocampal $\mathrm{CA}_{3}$ optical density divided by mean reticular formation density.

${ }^{b}$ Judged by visual inspection.

'Estimated from pre-2-DG $0.5 \mathrm{~Hz}$ stimulation to avoid artificially low ceiling values imposed by higher frequency stimulation. During post-2DG higher frequency stimulation, recorded units were essentially silent.

I). Hippocampal post-stimulation unit inhibition was directly proportional to relative hippocampal optical density ( $r=0.93 ; p \leq 0.01, t$ test for correlation). Each FF stimulation resulted in brief multiple-unit activity representing the arrival of single antidromic action potentials into some pyramidal cells, followed by an almost complete cessation of pyramidal firing until the next stimulation, when the pattern was repeated (Fig. 3). In the three animals with surgically isolated hippocampi, the above-described physiological effects of FF stimulation were confined to the ipsilateral hippocampus. In the one animal (no. 4) with a caudally displaced stimulating electrode, there was relatively brief pyramidal firing suppression lasting only $203 \mathrm{msec}$, as compared to at least $293 \mathrm{msec}$ in the other FF animals (Table I); note that this animal was the only one which failed to show enhanced hippocampal 2-DG uptake.

The medial septal nucleus (and nucleus of the diagonal band of Broca), the origin of "septohippocampal" fibers (Meibach and Siegel, 1977a; Swanson and Cowan, 1979), did not show enhanced 2-DG uptake in any animal, demonstrating that antidromic activation of cell bodies per se was not sufficient to increase 2-DG uptake. Moreover, the lateral septal nuclei, the destination of most hippocamposeptal and subiculoseptal fibers (Meibach and Siegel, 1977b; Swanson and Cowan, 1977; Alonso and Köhler, 1982), showed only slightly increased 2-DG uptake in the three intact FF animals, demonstrating that FF stimulation was not as effective in orthodromically activating septal recurrent circuitry (cf. McLennan and Miller, 1974) as it was in antidromically activating hippocampal recurrent circuitry.

No afterdischarges were observed during 2-DG administration in any FF-stimulated animal.

Entorhinal stimulation. The neurophysiological and metabolic effects of entorhinal (PP) stimulation were considerably more complex than with $\mathrm{FF}$ stimulation (Table II). Unlike FF stimulation, PP stimulation affected 2-DG uptake and CA unit activity primarily ipsilaterally, even in intact animals; this result is consistent with the known predominance of ipsilateral entorhinodentate connections in rats (Goldowitz et al., 1975; Zimmer and Hjorth-Simonsen, 1975). Three of seven "high frequency" (7 to $9 \mathrm{~Hz}$ ) PP stimulation animals had the

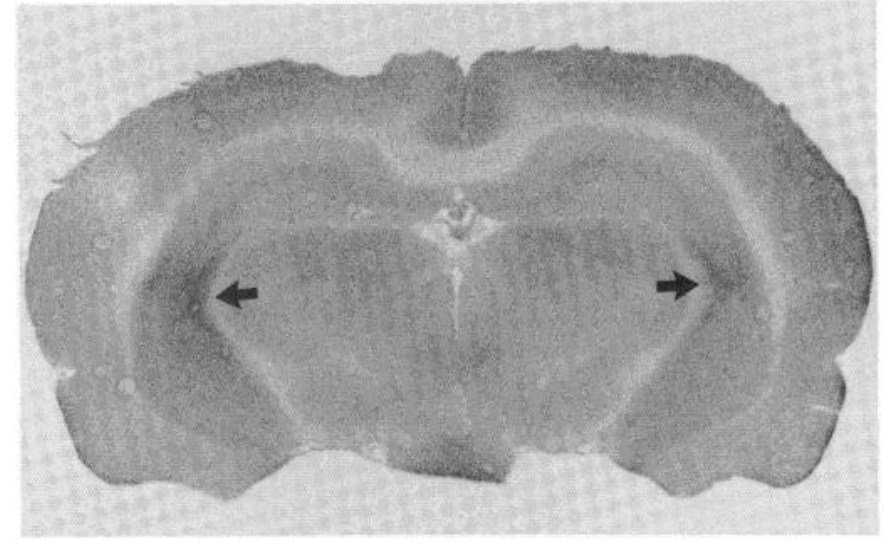

Figure 2. Typical result of FF stimulation (animal 13). Note the relatively increased $2-\mathrm{DG}$ uptake bilaterally along segments of the hippocampal pyramidal cell layers that lie opposite the arrows. In this and all subsequent figures stimulation was delivered to the left side.

expected increase in 2-DG uptake within the stratum moleculare of the ipsilateral dentate gyrus (Figs. 4 and $5 B$ ). Unit recordings from one of these three animals (no. 23) were unscorable; recordings from the other two animals (no.'s 5 and 19) revealed brief initial stimulationinduced excitation followed by firing suppression similar in duration to that induced by FF stimulation (Tables I and II; Fig. 6). Animal 5 had the most pronounced 2-DG uptake of any in the study (Fig. 4); it also was the only animal to show evidence of frank seizure-like activity, consisting of unusually large evoked potentials and several brief ( 4 to $11 \mathrm{sec}$ ) episodes of epileptiform afterdischarge that was independent of individual stimulations but was not self-sustaining upon momentary interruption of the stimulation (cf. Steriade, 1964; Cherlow et al., 1977). Interestingly, these episodes were not accompanied by increased firing in the recorded CA units. Animals 19 (Fig. 4) and 23 had hippocampal 2-DG uptake that was less intense but similar in pattern to animal 5 , indicating that, although the epileptiform activity observed in animal 5 may have affected the magnitude of stimulation-induced 2-DG labeling, it did not appreciably alter the uptake pattern (cf. Kliot and Poletti, 1979). In 
A

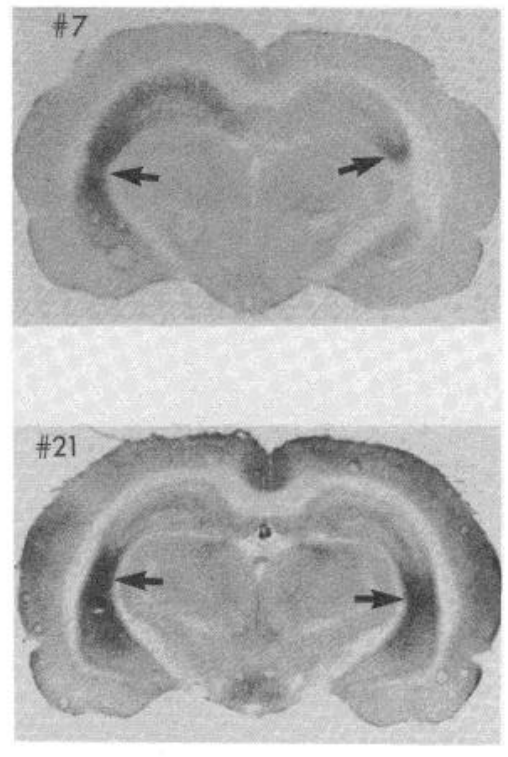

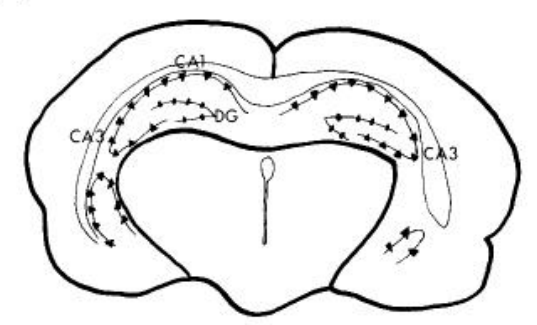

B

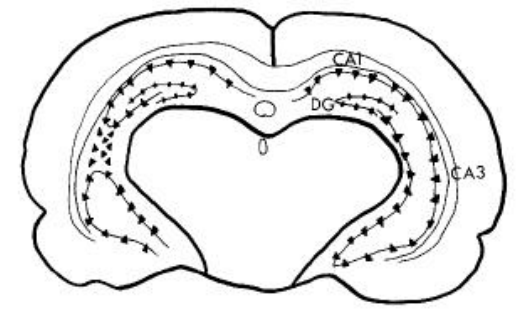

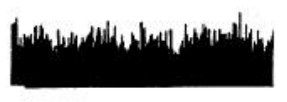

C
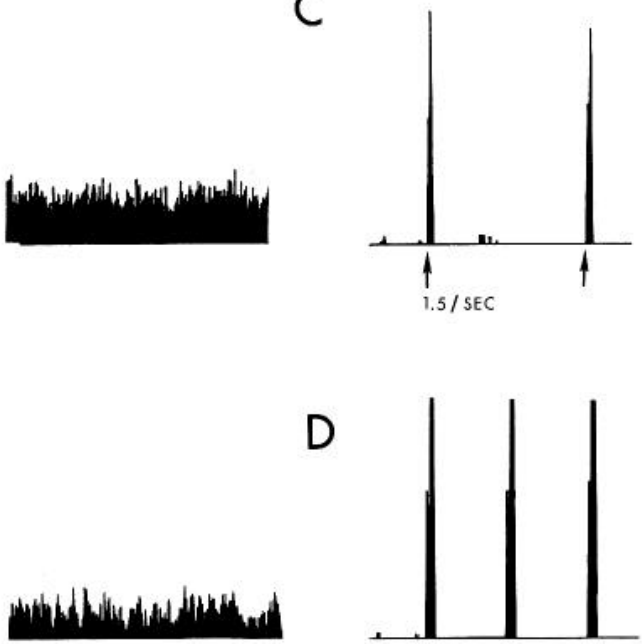

PRE INJECTION, BASELINE

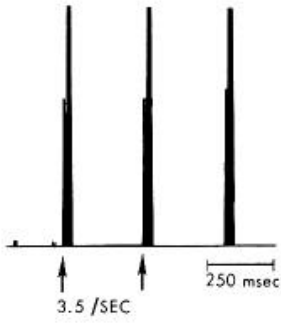

POST INJECTION, FORNIX STIMULATION

Figure 3. Two other FF animals. A, Autoradiogram and corresponding diagram for animal 7 ; $B$, autoradiogram and corresponding diagram for animal 21. Arrows indicate location of enhanced 2-DG uptake. $C$ and $D$, Post-stimulation time histograms of multiple pyramidal unit activity in animals 7 and 21, respectively, before (left) and during (right) FF stimulation. Arrows indicate occurrence of stimulations. The unit activity seen immediately after each stimulation represents a combination of stimulus artifact, evoked potentials and invasion of action potentials into some pyramidal cell bodies. Note the almost complete cessation of unit activity between stimulations. Abbreviations are as in Figure 1.

two other "high frequency" animals (no.'s 22 and 24) there was no appreciable change from normal hippocampal 2-DG uptake; however, animal 24 did have greatly increased ipsilateral ventral subicular and lateral septal uptake. The stimulation had no effect on the recorded CA units of these two animals.

In the remaining two "high frequency" PP stimulation animals (no.'s 20 and 25), and in all of the "low frequency" PP stimulation animals (no.'s, 8, 10, 15, and 16), there was a paradoxical decrease of 2-DG uptake within the normally dense stratum moleculare of the dentate gyrus (Fig. 7) and the distal stratum lacunosum-moleculare of the hippocampus (cf. Schwartz and Sharp, 1978; Lund et al., 1981). Unit recording revealed that within this subgroup, stimulation induced a brief excitation of CA neurons, followed by unit firing suppression that was significantly shorter than that induced by FF stimulation $\left(\overline{\mathrm{X}}_{\mathrm{msec}}=116 \pm 38(\mathrm{SEM})\right.$ versus $\overline{\mathrm{X}}_{\mathrm{msec}}=457 \pm 82(\mathrm{SEM})$; $p \leq 0.01, t$ test; compare Fig. 3 with Fig. 8). The ipsilaterally decreased 2-DG uptake suggests that in these animals the PP stimulation produced a net decrease rather than the expected increase in hippocampal excitation. However, an overall decrease in hippocampal unit activity could be documented in only one case (no. 20, Figs. 7 and 9) which was stimulated in the perirhinal region. Pre-2-DG $0.5 \mathrm{~Hz}$ stimulation induced a phasic mean CA unit firing suppression of only $83 \mathrm{msec}$ (Fig. 9, Preinjection, segment $b$ ). However, there was a longer period of slightly decreased firing that appeared quite distinct physiologically from the phasic component (Fig. 9 , left, segment $c$ ). When $7 \mathrm{~Hz}$ stimulation was begun, there was a tonic decrease in CA unit firing (Fig. 9,
Postinjection), also suggesting a decrease of the normal excitatory input to the hippocampus from the entorhinal cortex.

Two (animals 9 and 14) of three control animals in which unilateral entorhinal electrodes were implanted but not stimulated also showed slight fading of the ipsilateral stratum moleculare, suggesting that in these animals merely implanting the electrode was sufficient to reduce activity in PP terminals. However, fading in the two animals was small compared to several of the stimulated animals (see Table II). Moreover, the third control animal (no. 26) did not evidence any asymmetry in 2DG uptake even though the shaft of the entorhinal electrode was positioned immediately adjacent to the ipsilateral stratum moleculare.

Inhibition duration and 2-DG uptake. Hippocampal 2DG accumulation was poorly related to stimulation frequency in both FF and PP groups, with the exception that all three PP stimulation animals showing increased 2-DG uptake were among those stimulated at 7 to $9 \mathrm{~Hz}$ (Table II). Moreover, 2-DG accumulation was also poorly related to the occurrence of stimulation-induced unit bursts; for example, in several PP animals (e.g., animal 10, Fig. 8, lower right trace; animal 19, Fig. 6, lower $(R)$ trace) no increased 2-DG accumulation was observed in hippocampi which had displayed striking stimulationinduced bursting. Rather, the presence of increased 2DG uptake was highly related to the duration of CA unit firing suppression regardless of whether it was induced by FF or by PP stimulation; hippocampi with increased 2-DG uptake had a group mean suppression duration more than 3 times that of hippocampi with no $2-\mathrm{DG}$ 
increase $\left(\overline{\mathrm{X}}_{\mathrm{msec}} 447 \pm 68(\mathrm{SEM})\right.$ versus $\overline{\mathrm{X}}_{\mathrm{msec}}=128 \pm 35$ (SEM); $p \leq 0.01, t$ test), with an overlap of only one value between the two groups. Thus, inhibition of pyramidal unit firing, whether induced by FF or by PP stimulation, lasting approximately 265 msec (half the difference between the two overlapping values) or greater was associated with increased net metabolic demands over resting levels.

This latter point is well exemplified by the individual data from animal 19. Entorhinal stimulation produced increased 2-DG uptake in the ipsilateral statum moleculare, relative to its contralateral homologue (Fig. 4). Prestimulation, there was vigorous pyramidal multipleunit activity in both left and right CA fields (Fig. 6, Preinjection). The stimulation also produced robust evoked potentials and brief CA pyramidal firing bursts on both sides, followed by pyramidal firing suppression on both sides (Fig. 6, Postinjection). However, on the ipsilateral side the duration of CA pyramidal firing suppression was $258 \mathrm{msec}$, comparable to that induced by FF stimulation (Table I), but on the contralateral side the pyramidal firing suppression lasted only $106 \mathrm{msec}$, comparable to that of more typical entorhinal stimulation results (Table II). Thus, within this animal, as in the experiment as a whole, the greater CA 2-DG uptake was associated with the greater stimulation-induced principal unit firing suppression.

\section{Discussion}

In the present study, increased hippocampal 2-DG occurred during demonstrated inhibition of principal (pyramidal) neurons. Moreover, the magnitude of the

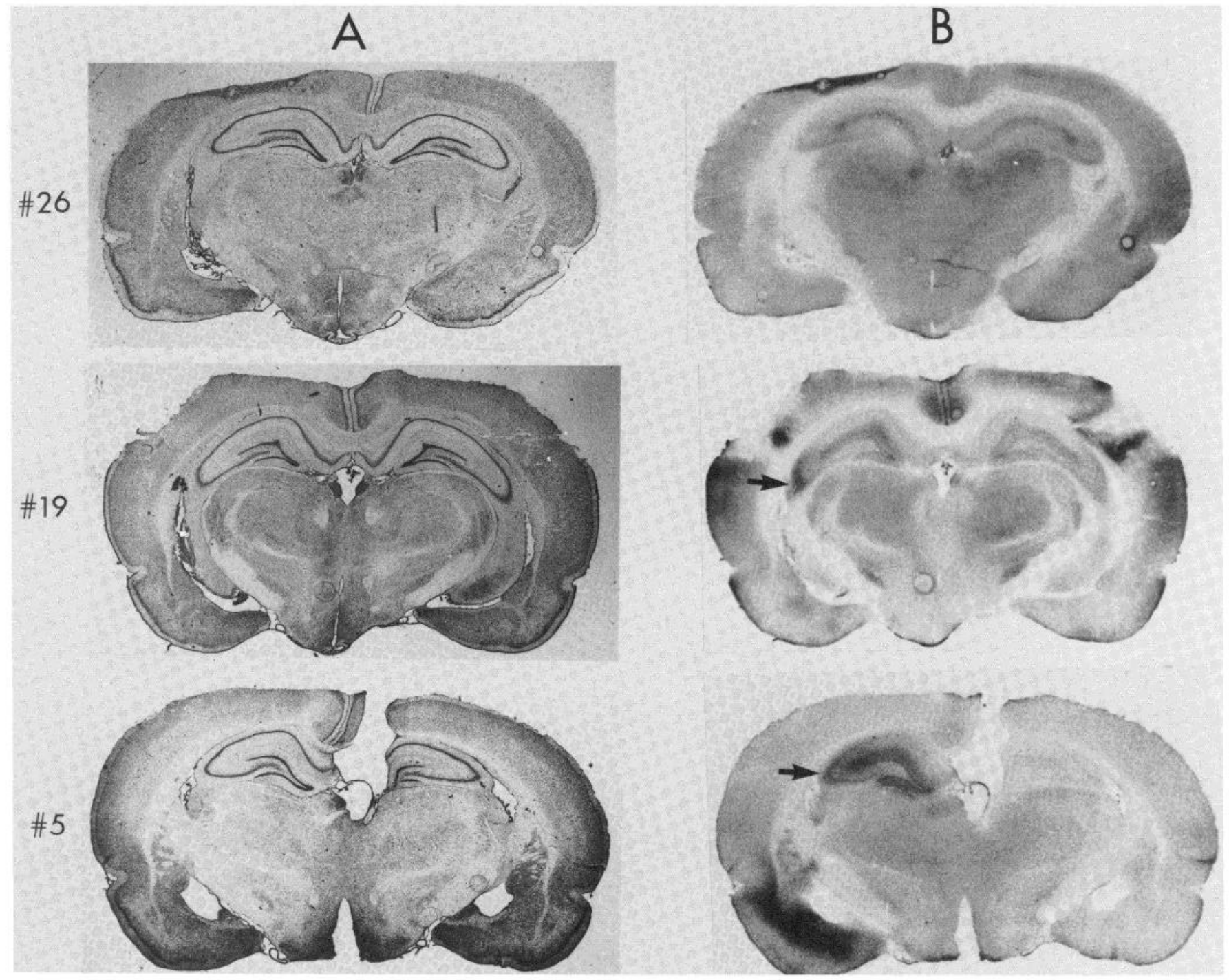

Figure 4. Cresyl violet stains $(A)$ and corresponding autoradiograms $(B)$ of the same sections from three animals (no.'s 26,19 , and 5). Animal 26 received no stimulation. Animal 19 received angular bundle/subicular stimulation. Animal 5, which had surgically isolated hippocampi, received entorhinal stimulation and displayed brief episodes of non-self-sustaining afterdischarge. Animal 19, with hippocampal commissure and fornices intact, nevertheless showed greater ipsilateral inhibition (cf. Fig. 6) and greater ipsilateral (arrow) 2-DG uptake. In animals 5 and 19, the PP stimulation conspicuously enhanced ipsilateral (arrow) dentate and $\mathrm{CA}_{3}$ uptake, while leaving $\mathrm{CA}_{1}$ uptake relatively unaffected. Abbreviations are as in Figure 1 . See also Figure 5. 
uptake was proportional to the duration of the principal cell inhibition. Even though this study was performed under conditions that emphasized recurrent and lateral inhibition (Nicoll et al., 1975; Alger and Nicoll, 1979; Mathers and Barker, 1980), each stimulation necessarily evoked both inhibitory and excitatory effects in some pyramidal cells. Therefore, it could be argued that the increased glucose utilization was due primarily to pyramidal excitation and that recurrent inhibition contributed relatively little to the increases. However, several facts weaken such an argument. (1) Prior severing of the fimbria, although it prevented increased lateral septal uptake, failed to prevent increased hippocampal uptake, thus demonstrating that any excitatory effects of septohippocampal stimulation were not necessary for increased hippocampal 2-DG uptake. (2) With FF stimu- lation, any given pyramidal cell receives at most only a single antidromic action potential per stimulation; in fact, because of the great divergence of interneuronal terminal arborization, most recorded pyramidal neurons evidence only a recurrent IPSP without a preceding action potential (Kandel et al., 1961; Dichter and Spencer, 1969; Yokota et al., 1970; Crow et al., 1977; Finch and Babb, 1977; Fujita, 1979). Moreover, in the present experiments pyramidal neurons were driven at relatively low frequencies ( $\mathrm{FF}$ stimulation; 2 to $4 \mathrm{~Hz}$ ), and each stimulation was followed by a long period of firing suppression; therefore, it is most likely that under antidromic stimulation each affected pyramidal cell fired at greatly reduced overall rates. (3) In contrast to FF stimulation, PP stimulation often resulted in obvious poststimulation pyramidal unit bursting (cf. Kandel et al.,
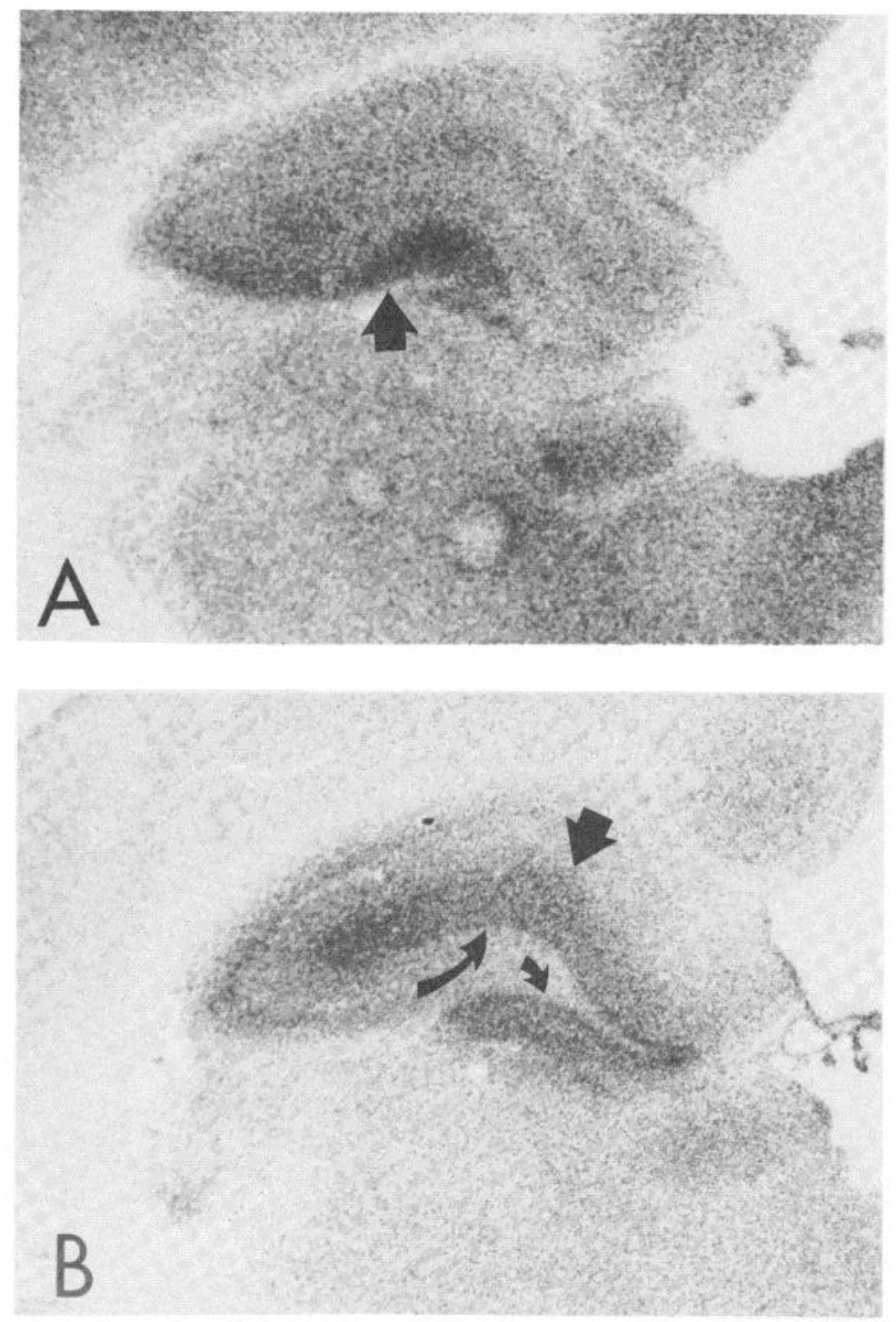

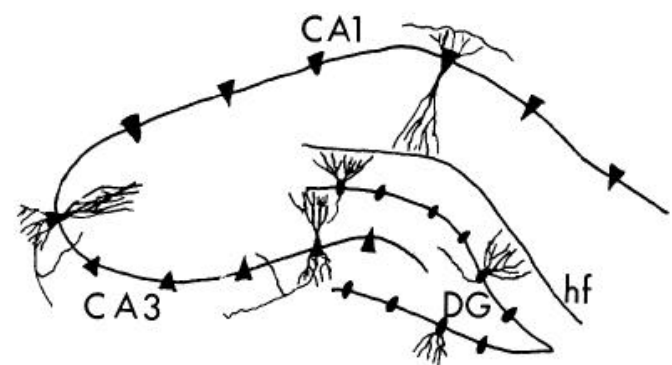

Figure 5. Higher magnification of the hippocampus of animal $5(B)$ together with animal $6(A)$, an FF animal. The accompanying diagram illustrates the position and orientation of dentate granule cells and of CA pyramidal cells. Note that FF stimulation enhanced 2-DG uptake in $\mathrm{CA}_{3}$, extending into the hilus of the dentate gyrus (arrow). In contrast, PP stimulation enhanced both $\mathrm{CA}_{3}$ and dentate gyrus uptake. Note also that the dentate uptake included both the stratum moleculare (large arrow) and stratum granulosum (curved arrows). 


\section{PRE INJECTION}

L

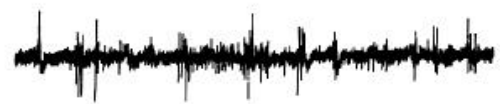

$\# 19$

$\mathbf{R}$

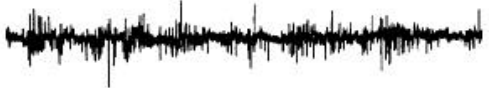

\# 5
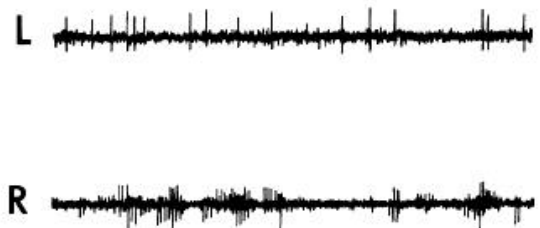

POST INJECTION

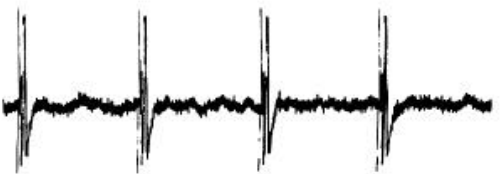

A
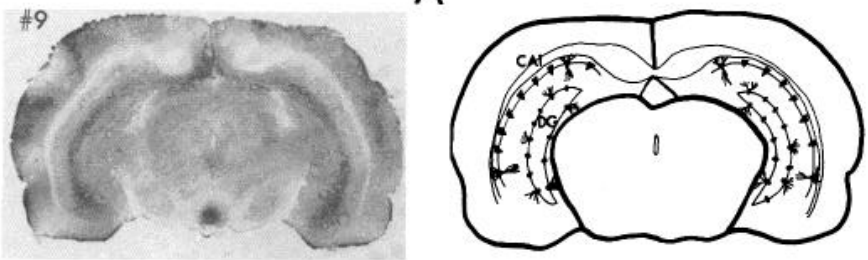

B
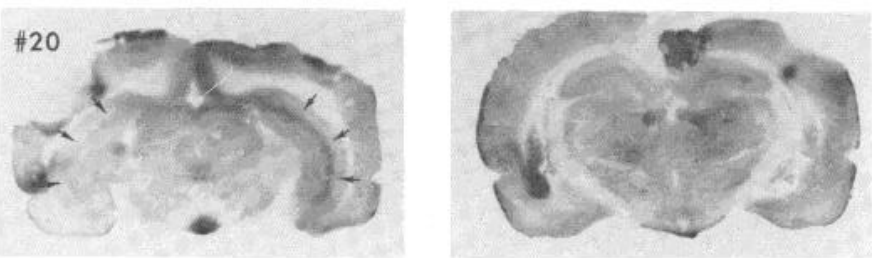

Figure 7. 2-DG uptake in a control animal (no. 9, $A$ ) and an animal receiving perirhinal stimulation (no. $20, B$ ). In the control there was symmetrical 2-DG uptake in the left and right strata moleculare. In the stimulated animal (no. 20, $B$, left) there was reduced uptake in the ipsilateral entorhinal cortex and hippocampal formation extending rostrally into the dorsal hippocampus (no. 20, B, right). The arrows indicate the location of the stratum moleculare. Abbreviations are as in Figure 1.

1961) in hippocampi that subsequently, however, failed to show supranormal 2-DG uptake. In fact, in several instances PP stimulation produced a paradoxical decrease in ipsilateral hippocampal 2-DG utilization. (4)

\section{RECOVERY}
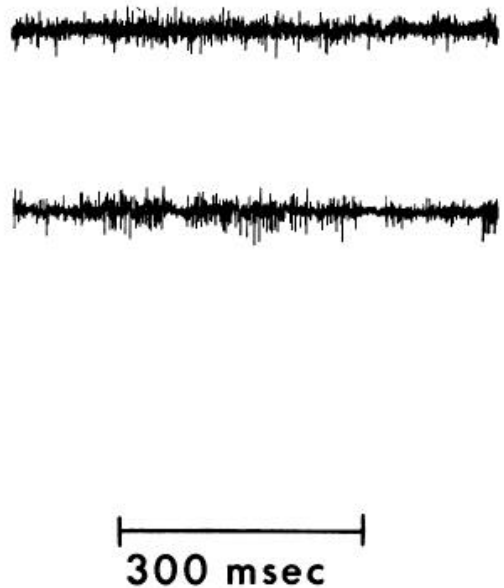
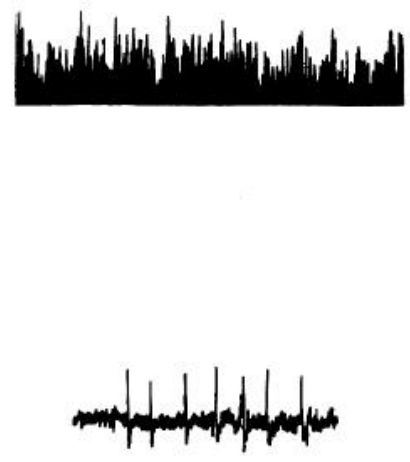

\section{PRE INJECTION, BASELINE}

Figure 8. Multiple-unit time histograms (top) and multipleunit recordings (bottom) from a PP stimulation animal (no. 10) that showed only a slight fading of the ipsilateral stratum moleculare. Note that each stimulation (arrows) produced only a short suppression of pyramidal unit firing. 


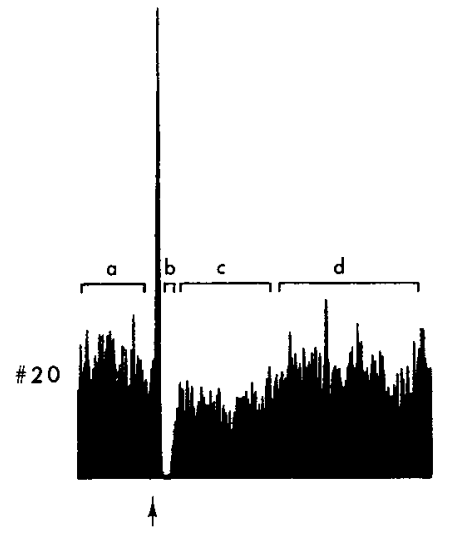

PRE INJECTION

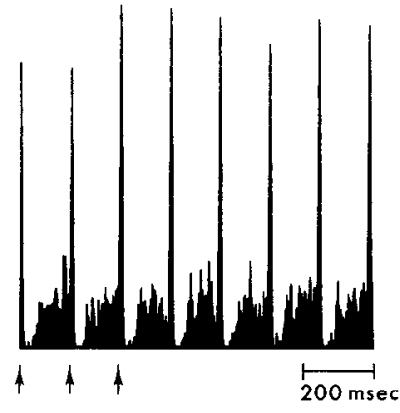

POST INJECTION
Figure 9. Multiple-unit time histograms from animal 20. Left, Low frequency $(0.5 \mathrm{~Hz})$ stimulation preceding $2-\mathrm{DG}$ administration. For approximately $80 \mathrm{msec}$ following each stimulation, unit firing suppression was complete $(b)$. Then, firing abruptly returned $(c)$, but at lower rates than base line $(a)$. Right, Higher frequency $(7 \mathrm{~Hz})$ stimulation following 2-DG administration. At this stimulation frequency, unit firing rates remained well below base line (cf. Fig. 7). Arrows indicate stimulation intervals.
With FF stimulation, abnormal medial septum/diagonal band uptake was never observed. Since the fimbria comprises septohippocampal as well as hippocamposeptal fibers, if excitatory effects per se of antidromic stimulation were responsible for increased hippocampal uptake, then the intact FF stimulation animals would be expected to show supranormal 2-DG uptake in the medial septum/nucleus diagonal band as well (cf. Yarowsky et al., 1980).

Although the technique used in the present study could not resolve 2-DG uptake within particular neuronal elements (i.e., neuropil versus cell bodies), it could readily be seen that increased uptake was particularly prominent in segments of the stratum pyramidale and adjacent stratum oriens, where most hippocampal interneurons are located (Lorente de Nó, 1934; Ramón y Cajal, 1955; Ribak et al., 1978). Although there are few interneurons relative to the number of pyramidal cells, each interneuron has greatly divergent terminal arborizations that collectively form a dense plexus of inhibitory axosomatic synapses upon pyramidal cell bodies (Andersen et al., 1969; Finch and Babb, 1977; Schwartzkroin and Mathers, 1978). Thus the observed 2-DG pattern was consistent with the notion that the increased uptake was largely

TABLE II

Entorhinal (PP) stimulation

\begin{tabular}{|c|c|c|c|c|c|c|}
\hline \multirow[t]{2}{*}{ Animal No. } & \multirow{2}{*}{$\begin{array}{l}\text { Condition of FF } \\
\text { and Hippocampal } \\
\text { Commissures }\end{array}$} & \multicolumn{2}{|c|}{$\begin{array}{l}\text { Stimulation } \\
\text { Parameters }\end{array}$} & \multirow{2}{*}{$\begin{array}{l}\text { Duration of } \\
\text { Inhibition } \\
\text { (msec) }\end{array}$} & \multirow{2}{*}{$\begin{array}{l}\text { Stratum } \\
\text { Moleculare } \\
\text { 2-DG ratio }\end{array}$} & \multirow{2}{*}{$\begin{array}{l}\text { Locus of Increased }(+) \\
\text { or Decreased }(-) \\
\text { 2-DG Uptake }\end{array}$} \\
\hline & & $\mathrm{Hz}$ & $\mu \mathrm{A}$ & & & \\
\hline 5 & severed & 8.8 & 180 & $680^{c}$ & 1.17 & $\begin{array}{l}(+) \text { ipsilateral caudal subiculum, } \mathrm{CA}_{1}, \mathrm{CA}_{3} \text {, stra- } \\
\text { tum moleculare, stratum granulosum, ento- } \\
\text { rhinal cortex, pyriform cortex, amygdala nu- } \\
\text { cleus accumbens }\end{array}$ \\
\hline 8 & inlact & 1.7 & 180 & 271 & 0.90 & (-) ipsilateral stratum moleculare \\
\hline 10 & intact & 3.4 & 180 & 18 & 0.90 & $\begin{array}{l}\text { (-) ipsilateral stratum moleculare, diffuse hip- } \\
\text { pocampal reduction }\end{array}$ \\
\hline 15 & severed & 1.6 & 360 & 144 & 0.70 & $\begin{array}{l}\text { (-) ipsilateral stratum moleculare, diffuse hip- } \\
\text { pocampal reduction }\end{array}$ \\
\hline 16 & severed & 1.9 & 800 & 150 & 0.87 & (-) ipsilateral stratum moleculare \\
\hline 19 & intact & 6.7 & 180 & $258^{c}$ & 1.14 & $\begin{array}{l}\text { (+) ipsilateral caudal } \mathrm{CA}_{1}, \mathrm{CA}_{3} \text {, subiculum, dor- } \\
\text { sal stratum moleculare, entorhinal cortex, lat- } \\
\text { eral septum }\end{array}$ \\
\hline 20 & intact & 6.7 & 180 & 83 & 0.74 & $\begin{array}{l}\text { (-) ipsilateral stratum moleculare } \\
\text { (+) ipsilateral subiculum, amygdala, lateral sep- } \\
\text { tum }\end{array}$ \\
\hline 22 & intact & 9.1 & 180 & 0 & 0.97 & no change \\
\hline 23 & intact & 8.0 & 360 & & 1.14 & $\begin{array}{l}\text { (+) ipsilateral caudal and dorsal } \mathrm{CA}_{3} \text {, hilus, } \\
\text { stratum moleculare }\end{array}$ \\
\hline 24 & intact & 7.7 & 360 & 0 & 1.06 & $\begin{array}{l}\text { (+) ipsilateral subiculum, lateral septum, no } \\
\text { change in hippocampus }\end{array}$ \\
\hline 25 & intact & 7.7 & 360 & 30 & 0.81 & (-) ipsilateral stratum moleculare \\
\hline 9 & intact & \multicolumn{2}{|c|}{ control } & & 0.94 & (-) ipsilateral stratum moleculare \\
\hline 14 & intact & \multicolumn{2}{|c|}{ control } & & 0.91 & $\begin{array}{l}\text { (-) ipsilateral stratum moleculare, diffuse hip- } \\
\text { pocampal reduction }\end{array}$ \\
\hline 26 & intact & \multirow{2}{*}{\multicolumn{2}{|c|}{ control }} & & 1.01 & no change \\
\hline \multicolumn{5}{|c|}{$\overline{\mathrm{X}}=204 \pm 76(\mathrm{SEM})^{d}$} & & \\
\hline
\end{tabular}

${ }^{a}$ Mean ipsilateral stratum moleculare optical density divided by mean contralateral stratum moleculare optical density.

${ }^{b}$ Judged by visual inspection.

${ }^{c}$ See Footnote $c$ of Table I.

${ }^{d}$ Control and zero values not computed in the mean; significantly different from $\mathrm{FF}$ group $(p \leqslant 0.05, t$ test). 
due to activation of recurrent inhibitory circuitry, particularly interneuronal terminals (cf. Sharp, 1976b).

Up to a point, the energy demand of active inhibitory terminals should be offset by energy savings derived from the consequently reduced firing rates of inhibited postsynaptic neurons (Granit and Rutledge, 1960; Knowles and Schwartzkroin, 1981; see Collins, 1978, 1980, for discussion). However, once there is sufficient inhibitory neuronal activity to prevent postsynaptic neurons from firing, any further increase in interneuronal activity will result in additional energy demand that cannot be offset by further savings from already silent principal cells. In the present study, obviously increased hippocampal 2DG uptake occurred reliably whenever post-stimulation suppression of pyramidal unit activity exceeded approximately $265 \mathrm{msec}$, suggesting that this duration of pyramidal unit inhibition corresponded to the above-described optimal level of interneuronal firing beyond which any greater activity resulted in progressively increased net regional "total metabolic work" (Sharp, 1976c).

The present study's findings imply that the activity level of principal neurons cannot be confidently inferred from $\left[{ }^{14} \mathrm{C}\right]-2-\mathrm{DG}$ autoradiograms (cf. Hubel et al., 1978; Auker et al., 1983), primarily because of the great uncertainty concerning which of many distinct neuronal and glial energy-requiring mechanisms may be most responsible for observed deviations in a given region's 2-DG uptake. Distinguishing predominantly "excited" regions from predominantly "inhibited" regions is equally difficult because neuronal excitation and inhibition involve metabolically similar mechanisms. For example, brain metabolic demand appears to be strongly associated with neuronal activity (McIlwain et al., 1951; Kennedy et al., 1975; Sharp, 1976a, b; Miyaoka et al., 1979; Yarowsky et al., 1979; Schoppmann and Stryker, 1980; Allen et al., 1981; Sharp et al., 1981; Toga and Collins, 1981; Macko et al., 1982; Wieraszko, 1982), and the single greatest energy requirement appears to come from the $\mathrm{Na}^{+}-\mathrm{K}^{+}$ pump (Whittam, 1962; Mata et al., 1980), which is necessary for maintenance and restoration of resting ion concentrations regardless of whether a given neuron secretes excitatory or inhibitory transmitter. Moreover, in many cases excitatory and inhibitory neurons are spatially intermingled and physiologically interlocked (Andersen and Eccles, 1962; Szentagothai, 1979; Knowles and Schwartzkroin, 1981), making it virtually impossible to affect one class of neurons without also affecting the other to some degree. Therefore, any experimentally induced hypermetabolic region probably is one in which both excitatory and inhibitory neurons are usually active. For example, Hubel et al. (1978) observed that single-orientation visual stimuli induced vertical 2DG bands in the visual cortex that were as wide as several physiologically defined cortical orientation columns (Hubel and Wiesel, 1974). Many studies have implicated lateral and recurrent inhibition in visual cortical processing of oriented stimuli (e.g., Blakemore and Tobin, 1972; Creutzfeldt et al., 1974; Rose and Blakemore, 1974; Hess et al., 1975; Tsumoto et al., 1979). Thus, the width of the 2-DG bands observed by Hubel et al. (1978) can be accounted for by postulating that each band comprised a central, optimally stimulated, functional column plus several laterally inhibited columns to either side of the optimally stimulated column (cf. Fig. 2 of Hubel et al., 1978; Benevento et al., 1972; Sillito et al., 1980). Conversely, a hypometabolic region probably is one in which both excitatory and inhibitory neurons are unusually inactive. For example, Tootell et al. (1981), in a study similar in concept to that of Hubel et al. (1978), observed that single-frequency spatial stimuli produced vertical bands of hypometabolism between bands of hypermetabolism. Collins (1978, 1980), using penicillin applied to neocortex, also produced bands of hypometabolism adjacent to hypermetabolic regions. In these and other studies it was suggested that such hypometabolic regions were "inhibited." However, the present results imply that reduced net regional energy demand is not a likely outcome of vigorous active inhibition. Rather, in the above-cited studies hypometabolism was possibly the consequence of reduced input from the laterally inhibited fringes of neighboring hypermetabolic regions (cf. Grant et al., 1975; Goldman and Nauta, 1977; Colombo and Saporta, 1980).

The present report confirms that the ability of the 2 DG technique to reveal brain function is increased significantly by simultaneous measurement of neurophysiological variables. Future research utilizing techniques having greater resolution (e.g., Ryan and Sharp, 1982), together with concomitant and independent measures of physiological function, is needed to allow confident attribution of alterations in glucose metabolism to specific synaptic mechanisms.

\section{References}

Alger, B. E., and R. A. Nicoll (1979) GABA-mediated biphasic inhibitory response in hippocampus. Nature 281: 315-317.

Allen, G. I., J. C. Eccles, R. A. Nicoll, T. Oshima, and F. J. Rubia (1977) The ionic mechanisms concerned in generating the i.p.s.p.s of hippocampal pyramidal cells. Proc. R. Soc. Lond. (Biol.) 198: 363-384.

Allen, T. O., N. T. Adler, J. H. Greenberg, and M. Reivich (1981) Vaginocervical stimulation selectively increases metabolic activity in the rat brain. Science 211: 1070-1072.

Alonso, A., and C. Köhler (1982) Evidence for separate projections of hippocampal pyramidal and non-pyramidal neurons to different parts of the septum in the rat brain. Neurosci. Lett. 31: 209-214.

Andersen, P., and J. Eccles (1962) Inhibitory phasing of neuronal discharge. Nature 196: 645-647.

Andersen, P., J. C. Eccles, and Y. Løyning (1964a) Location of postsynaptic inhibitory synapses on hippocampal pyramids. J. Neurophysiol. 27: 592-607.

Andersen, P., J. C. Eccles, and Y. Løyning (1964b) Pathway of postsynaptic inhibition in the hippocampus. Neurophysiology 27: 608-619.

Andersen, P., B. Holmqvist, and P. E. Voorhoeve (1966a) Entorhinal activation of dentate granule cells. Acta Physiol. Scand. 66: 448-460.

Andersen, P., B. Holmqvist, and P. E. Voorhoeve (1966b) Excitatory synapses on hippocampal apical dendrites activated by entorhinal stimulation. Acta Physiol. Scand. 66: 461-472.

Andersen, P., G. N. Gross, T. Lømo, and O. Sveen (1969) Participation of inhibitory and excitatory interneurons in 
the control of hippocampal cortical output. In The Interneuron, M. A. B. Brazier, ed. pp. 415-465, University of California Press, Berkeley.

Anderson, T. E., and L. T. Rutledge (1979) Inhibition of penicillin-induced epileptic foci. Electroencephalogr. Clin. Neurophysiol. 46: 498-509.

Auker, C. R., R. M. Meszler, and D. O. Carpenter (1983) Apparent discrepancy between single-unit activity and $\left[{ }^{14} \mathrm{C}\right]$ deoxyglucose labeling in optic tectum of the rattlesnake. J. Neurophysiol. 49: 1504-1516.

Benevento, L. A., O. D. Creutzfeldt, and V. Kuhnt (1972) Significance of intracortical inhibition in the visual cortex. Nature New Biol. 238: 124-126.

Blakemore, C., and E. A. Tobin (1972) Lateral inhibition between orientation detectors in the cat's visual cortex. Exp. Brain Res. 15: 439-440.

Bland, B. H., P. Andersen, T. Ganes, and O. Sveen (1980) Automated analysis or rhythmicity of physiologically identified hippocampal formation neurons. Exp. Brain Res. 38: 205-219.

Buzsáki, G., and E. Eidelberg (1981) Commissural projection to the dentate gyrus of the rat: Evidence for feed forward inhibition. Brain Res. 230: 346-350.

Caveness, W. F., M. Kato, B. L. Malamut, S. Hosokawa, S. Wakisaka, and R. R. O'Neill (1980) Propagation of focal motor seizures in the pubescent monkey. Ann. Neurol. 7: $213-221$.

Cherlow, D. G., A. M. Dymond, P. H. Crandall, R. D. Walter, and E. A. Serafatinides (1977) Evoked response and after discharge thresholds to electrical stimulation in temporal lobe epileptics. Arch. Neurol. 34: 527-531.

Collins, R. C. (1978) Use of cortical circuits during focal penicillin seizures: An autoradiographic study with $\left[{ }^{14} \mathrm{C}\right]$ deoxy glucose. Brain Res. 150: 487-501.

Collins, R. C. (1980) Intracortical localization of 2-deoxyglucose metabolism: On-off metabolic columns. In Cerebral Metabolism and Neural Function, J. V. Passonneau, R. A. Hawkins, W. D. Lust, and F. A. Welsh, eds., pp. 338-351, Williams and Wilkins, Baltimore.

Colombo, J. A., and S. Saporta (1980) Increased local uptake of 2-deoxyglucose after electrochemical or direct deposition of iron into the rat brain. Exp. Neurol. 70: 427-437.

Coombs, J. S., J. C. Eccles, and P. Fatt (1955) The specific ionic conductances and the ionic movements across the motoneuronal membrane that produce the inhibitory post-synaptic potential. J. Physiol. (Lond.) 130: 326-373.

Creutzfeldt, O. D. (1975) Neurophysiological correlates of different functional states of the brain. In Brain Work: The Coupling of Function, Metabolism and Blood Flow in the Brain, D. H. Ingvar and N. A. Lassen, eds., pp. 21-46, Munksgaard, Copenhagen.

Creutzfeldt, O. D., U. Kuhnt, and L. A. Beneveto (1974) An intracellular analysis of visual cortical neurons to moving stimuli: Responses in a cooperative neuronal network. Exp. Brain Res. 21: 251-274.

Crow, T. J., D. M. Finch, and T. L. Babb (1977) Absence of cerebellar influences on hippocampal neurons in the cat. Exp. Neurol. 57: 486-505.

Daitz, H. M., and T. P. S. Powell (1954) Studies of the connexions of the fornix system. J. Neurol. Neurosurg. Psychiatry 17: $75-82$.

Dichter, M., and W. A. Spencer (1969) Penicillin-induced interictal discharges from the cat hippocampus. I. Characteristics and topographical features. J. Neurophysiol. 32: 649662.

Di Rocco, R. J. and W. G. Hall (1981) Metabolic neural mapping in neonatal rats. J. Neurosci. Res. 6: 13-19.

Doller, H. J., and F. F. Weight (1982) Perforant pathway activation of hippocampal CA1 stratum pyramidale neurons: Electrophysiological evidence for a direct pathway. Brain Res. 237: 1-13.

Dudek, F. E., S. A. Deadwyler, C. W. Cotman, and G. Lynch (1976) Intracellular responses from granule cell layer in slices of rat hippocampus: Perforant path synapse. J. Neurophysiol. 39: 384-393.

Eccles, J. C. (1967) Postsynaptic inhibition in the central nervous system. In The Neurosciences-A Study Program, G. C. Quarton, T. Melnechuk, and F. O. Schmitt, eds., pp. 408-427, Rockefeller University Press, New York.

Eccles, J. C. (1969) The Inhibitory Pathways of the Central Nervous System, Charles C Thomas, Springfield, IL.

Eccles, J. C., P. Fatt, and K. Koketsu (1954) Cholinergic and inhibitory synapses in a pathway from motor-axon collaterals to motoneurones. J. Physiol. (Lond.). 126: 524-562.

Finch, D. M., and T. L. Babb (1977) Response decrement in a hippocampal basket cell. Brain Res. 130:354-359.

Finch, D. M., and T. L. Babb (1980) Neurophysiology of the caudally directed hippocampal efferent system in the rat: Projections to the subicular complex. Brain Res. 197: 11-26.

Fujita, Y. (1979) Evidence for the existence of inhibitory postsynaptic potentials in dendrites and their functional significance in hippocampal pyramidal cells of adult rabbits. Brain Res. 179: 59-69.

Goldman, P. S., and W. J. H. Nauta (1977) Columnar distribution of cortico-cortical fibers in the frontal association, limbic, and motor cortex of the developing rhesus monkey. Brain Res. 122: 393-413.

Goldowitz, D., W. F. White, O. Steward, G. Lynch, and C Cotman (1975) Anatomical evidence for a projection from the entorhinal cortex to the contralateral dentate gyrus of the rat. Exp. Neurol. 47: 433-441.

Granit, R., and L. T. Rutledge (1960) Surplus excitation in reflex action of motoneurons as measured by recurrent inhibition. J. Physiol. (Lond.) 154: 288-307.

Grant, G., S. Landgren, and H. Silfvenius (1975) Columnar distribution of $U$-fibres from the postcruciate cerebral projection area of the cat's group I muscle afferents. Exp. Brain Res. 24: 57-74.

Hagiwara, S., and I. 'I'asaki (1958) A study on the mechanism of impulse transmission across the giant synapse of the squid. J. Physiol. (Lond.) 143: 114-137.

Hess, R., K. Negishi, and O. Creutzfeldt (1975) The horizontal spread of intracortical inhibition in the visual cortex. Exp. Brain Res. 22: 415-419.

Hubel, D. H., and T. N. Wiesel (1974) Sequence regularity and geometry of orientation columns in the monkey striate cortex. J. Comp. Neurol. 158: 295-306.

Hubel, D. H., T. N. Wiesel, and M. P. Stryker (1978) Anatomical demonstration of orientation columns in macaque monkey. J. Comp. Neurol. 177: 361-380.

Kandel, F. R., W. A. Spencer, and F. T. Rrinley, Jr. (1961) Electrophysiology of hippocampal neurons. I. Sequential invasion and synaptic organization. J. Neurophysiol. 24: 225242.

Kennedy, C., M. H. Des Rosiers, M. Reivich, F. Sharp, J. W. Jehle, and L. Sokoloff (1975) Mapping of functional neural pathways by autoradiographic survey of local metabolic rate with $\left[{ }^{14} \mathrm{C}\right]$ deoxyglucose. Science 187: 850-853.

Kliot, M., and C. E. Poletti (1979) Hippocampal afterdischarges: Differential spread of activity shown by the $\left[{ }^{14}\right] \mathrm{C}$ deoxyglucose technique. Science 204: 641-643.

Knowles, W. D., and P. A. Schwartzkroin (1981) Local circuit synaptic interactions in hippocampal brain slices. J. Neurosci. 1: 318-322.

König, J. F. R., and R. A. Klippel (1975) The Rat Brain: A Stereotaxic Atlas of the Forebrain and Lower Parts of the 
Brain Stem, Krieger Publishing Co., Huntington, NY.

Kuhl, D. E., J. Engel, Jr., M. E. Phelps, and C. Selin (1980) Epileptic patterns of local cerebral metabolism and perfusion in humans determined by emission computed tomography of ${ }^{18} \mathrm{FDG}$ and ${ }^{13} \mathrm{NH}_{3-}$ Neurol. 8: 348-360.

Lorente de Nó, R. (1934) Studies on the structure of the cerebral cortex. II. Continuation of the study of the Ammonic system. J. Psychol. Neurol. 46: 113-177.

Lund, J. P., J. J. Miller, and J. Courville (1981) $\left[{ }^{3} \mathrm{H}\right]$-Deoxy-dglucose capture in the hippocampus and dentate gyrus of ketamine-anesthetized rat. Neurosci. Lett. 24: 149-153.

Lux, H. D. (1971) Ammonium and chloride extrusion: Hyperpolarizing synaptic inhibition in spinal motoneurones. Science 173: 555-557.

Macko, K. A., C. D. Jarvis, C. Kennedy, M. Miyaoka, M. Shinohara, L. Sokoloff, and M. Mishkin (1982) Mapping the primate visual system with $\left[2-{ }^{14} \mathrm{C}\right]$ deoxyglucose. Science 218 : 394-397.

Mata, M., D. J. Fink, H. Gainer, C. B. Smith, L. Davidsen, H. Savaki, W. J. Schwartz, and L. Sokoloff (1980) Activitydependent energy metabolism in rat posterior pituitary primarily reflects sodium pump activity. J. Neurochem. 34: 213215.

Mathers, D. A., and J. L. Barker (1980) (-)-Pentobarbital opens ion channels of long duration in cultured mouse spinal neurons. Science 209: 507-509.

McIlwain, H., G. Anguiano, and J. D. Cheshire (1951) Electrical stimulation in vivo of the metabolism of glucose by mammalian cerebral cortex. Biochem. J. 50:12-18.

McLennan, H., and J. J. Miller (1974) The hippocampal control of neuronal discharges in the septum of the rat. J. Physiol (Lond.) 237: 607-624.

McNaughton, B. L., and C. A. Barnes (1977) Physiological identification and analysis of dentate granule cell responses to stimulation of the medial and lateral perforant pathways in the rat. J. Comp. Neurol. 175: 439-454.

Meibach, R. C., and A. Siegal (1977a) Efferent connections of the septal area in the rat: An analysis utilizing retrograde and anterograde transport methods. Brain Res. 119: 1-20.

Meibach, R. C., and A. Siegel (1977b) Efferent connections of the hippocampal formation in the rat. Brain Kes. 124: 197224.

Miyaoka, M., M. Shinohara, M. Batipps, K. D. Pettigrew, C. Kennedy, and L. Sokoloff (1979) The relationship between the intensity of the stimulus and the metabolic response in the visual system of the rat. Acta Neurol. Scand. Suppl. (72) 60: $16-17$.

Murphy, J. T., and L. P. Renaud (1969) Mechanisms of inhibition in the ventromedial nucleus of the hypothalamus. J. Neurophysiol. 32: 85-102.

Nicoll, R. A., J. C. Eccles, T. Oshima, and F. Rubia (1975) Prolongation of hippocampal inhibitory postsynaptic potentials by barbiturates. Nature 258: 625-627.

Plum, F., A. Gjedde, and F. E. Samson, eds. (1976) Neuroanatomical functional mapping by the radioactive 2-deoxy- $d$ glucose method. Neurosci. Res. Program Bull. 14: 455-518.

Ramón y Cajal, S. (1955) Studies on the Cerebral Cortex (Limbic Structures) L. M. Kraft, transl., Lloyd-Luke, London.

Rang, H. P., and J. M. Ritchie (1968) On the electrogenic sodium pump in mammalian non-myelinated nerve fibres and its activation by various external cations. J. Physiol (Lond.) 196: 183-221.

Renshaw, B. (1946) Central effects of centripetal impulse in axons of spinal ventral roots. J. Neurophysiol. 9: 191-204.

Ribak, C. E., J. E. Vaughn, and K. Sato (1978) Immunocytochemical localization of glutamic acid decarboxylase in neuronal somata following colchicine inhibition of axonal transport. Brain Res. 140: 315-332.
Rose, D., and C. Blakemore (1974) Effects of bicuculline on functions of inhibition in visual cortex. Nature 249: 75-77.

Ryan, A. F., and F. R. Sharp (1982) Localization of $\left[{ }^{3} \mathrm{H}\right] 2$ deoxyglucose at the cellular level using freeze-dried tissue and dry-looped emulsion. Brain Res. 252: 177-180.

Schoppmann, A., and M. P. Stryker (1980) Relationship between discharge frequency and glucose utilization in visual cortex of cat and kitten. Soc. Neurosci. Abstr. 6: 314.

Schwartz, W. J., and F. R. Sharp (1978) Autoradiographic maps of regional brain glucose consumption in resting, awake rats using $\left[{ }^{14} \mathrm{C}\right] 2$-deoxyglucose. J. Comp. Neurol. 177: 335-360.

Schwartz, W. J., C. B. Smith, L. Davidsen, H. Savaki, L. Sokoloff, M. Mata, D. J. Fink, and II. Gainer (1979) Metabolic mapping of functional activity in the hypothalamoneurohypophyseal system of the rat. Science 205: 723-725.

Schwartzkroin, P. A., and L. H. Mathers (1978) Physiological and morphological identification of a nonpyramidal hippocampal cell type. Brain Res. 157: 1-10.

Sharp, F. R. (1976a) Rotation induced increases of glucose metabolism in rat vestibular nuclei and vestibulo-cerebellum. Brain Res. 110: 141-151.

Sharp, F. R. (1976b) Relative cerebral glucose uptake of neuronal perikarya and neuropil determined with 2 deoxyglucose in resting and swimming rat. Brain Res. 110: 127-139.

Sharp, F. R. (1976c) Relation of central nervous system glucose metabolism to neuronal structure: General motor activity. Neurosci. Res. Program Bull. 14: 492-496.

Sharp, F. R., A. F. Ryan, P. Goodwind, and N. K. Woolf (1981) Increasing intensities of wide band noise increase $\left[{ }^{14} \mathrm{C}\right] 2$ deoxyglucose uptake in gerbil central auditory structures. Brain Res. 230: 87-96.

Sillito, A. M., J. A. Kemp, J. A. Milson, and N. Berardi (1980) $A$ reevaluation of the mechanisms underlying simple cell orientation selectivity. Brain Res. 194: 517-520.

Sokoloff, L. (1977) Relation between physiological function and energy metabolism in the central nervous system. J. Neurochem. 29: 13-26.

Sokoloff, L. (1981) Localization of functional activity in the central nervous system by measurement of glucose utilization with radioactive deoxyglucose. J. Cereb. Blood Flow Metab. 1: 7-36.

Sokoloff, L., M. Reivich, C. Kennedy, M. H. Des Rosiers, C. S. Patlack, K. D. Pettigrew, O. Sakurada, and M. Shinohara (1977) The $\left[{ }^{14} \mathrm{C}\right]$ deoxyglucose method for the measurement of local cerebral glucose utilization: Theory, procedure, and normal values in the conscious and anesthetized albino rat. J. Neurochem. 28: 897-916.

Steriade, M. (1964) Development of evoked responses into selfsustained activity within amygdalo-hippocampal circuits. Electroencphalogr. Clin. Neurophysiol. 16: 221-236.

Swanson, L. W., and W. M. Cowan (1977) An autoradiographic study of the organization of the efferent connections of the hippocampal formation in the rat. J. Comp. Neurol. 172: 4984.

Swanson, L. W., and Cowan, W. M. (1979) The connections of the septal region in the rat. J. Comp. Neurol. 186: 621-656.

Szentagothai, J. (1979) Local neuron circuits of the neocortex. In The Neurosciences: Fourth Study Program, F. O. Schmitt and F. G. Worden, eds., pp. 399-415, MIT Press, Cambridge, MA.

Takeuchi, A., and N. Takeuchi (1962) Electrical changes in pre- and post-synaptic axons of the giant synapse of Loligo. J. Gen. Physiol. 45: 1181-1193.

Tang, C. -M., M. W. Cohen, and R. K. Orkand (1980) Electrogenic pumps in axons and neuroglia and extracellular potassium homeostasis. Brain Res. 194: 283-286.

Toga, A. W., and R. C. Collins (1981) Metabolic response of optic centers to visual stimuli in the albino rat: Anatomical 
and physiological considerations. J. Comp. Neurol. 199: 443464.

Tootell, R. B., M. S. Silverman, and R. L. De Valois (1981) Spatial frequency columns in primary visual cortex. Science 214: 813-815.

Tsumoto, T., W. Eckart, and O. D. Creutzfeldt (1979) Modification of orientation sensitivity of visual cortex neurons by removal of GABA mediated inhibition. Exp. Brain Res. 34: $351-363$.

Whittam, R. (1962) The dependence of the respiration of brain cortex on active cation transport. Biochem. J. 82: 205-212.

Wieraszko, A. (1982) Changes in the hippocampal slice's energy metabolism following stimulation and long-term potentiation of Schaffer collaterals-Pyramidal cell synapses tested with the 2-dcoxyglucose technique. Brain Res. 237: 449-457.

Yamamoto, C. (1972) Activation of hippocampal neurons by mossy fiber stimulation in thin brain sections in vitro. Exp.
Brain Res. 14: 423-435.

Yarowsky, P., J. Jehle, D. H. Ingvar, and L. Sokoloff (1979) Relationship between functional activity and glucose utilization in the rat superior cervical ganglion in vivo Soc. Neurosci. Abstr. 5: 421.

Yarowsky, P., A. M. Crane, and L. Sokoloff (1980) Stimulation of neuronal glucose utilization by antidromic electrical stimulation in the superior cervical ganglion of the rat. Soc. Neurosci. Abstr. 6: 340.

Yokota, T., A. G. Reeves, and P. D. MacLean (1970) Differential effects of septal and olfactory volleys on intracellular responses of hippocampal neurons in awake, sitting monkeys. J. Neurophysiol. 33: 96-107.

Zimmer, J., and H. Hjorth-Simonsen (1975) Crossed pathways from the entorhinal arca to the fascia dentata. II. Provokable in rats. J. Comp. Neurol. 161: 71-102. 